\title{
Erratum: Non-marine fishes of the late Santonian Milk River Formation of Alberta, Canada - evidence from vertebrate microfossil localities
}

\section{Donald B. Brinkman, ${ }^{\star, 1,2}$ Andrew G. Neuman ${ }^{1}$ and Julien D. Divay ${ }^{1}$}

${ }^{1}$ Royal Tyrrell Museum of Palaeontology Drumheller, Alberta, T0J 1B0, Canada; don.brinkman@gov.ab.ca

${ }^{2}$ Adjunct, Department of Biological Sciences, University of Alberta Edmonton, Alberta Canada T6G 2E9

In our recent publication of the fishes from the Milk River Formation (Brinkman et al. 2017), Figure 20 was replaced in final editing by a duplication of Figure 21. The correct Figure 20 is presented on the opposite page.

Figure 20. Acanthomorph centra from the Milk River Formation. A-C) first centra showing variation in the development of struts along the side of the centrum: A, UALVP 56052; B, UALVP 48903; C, TMP 2000.2.57. D-F) precaudal centra showing variation in development of struts and ridges on the lateral and dorsal surface of the centrum: D, UALVP 48907; E, UALVP 17397(a); F) UALVP 17397(b). Centra shown in anterior, left lateral, posterior, dorsal and ventral views. Scale bar equals $2 \mathrm{~mm}$.

\section{LITERATURE CITED}

Brinkman, D.B., A.G. Neuman, and J.D. Divay. 2017. Nonmarine fishes of the late Santonian Milk River Formation of Alberta, Canada - evidence from vertebrate microfossil localities. Vertebrate Anatomy Morphology Palaeontology 3:7-46.

* corresponding author

Published April 11, 2017

(c) 2017 by the authors

DOI 10.18435/B5D598 

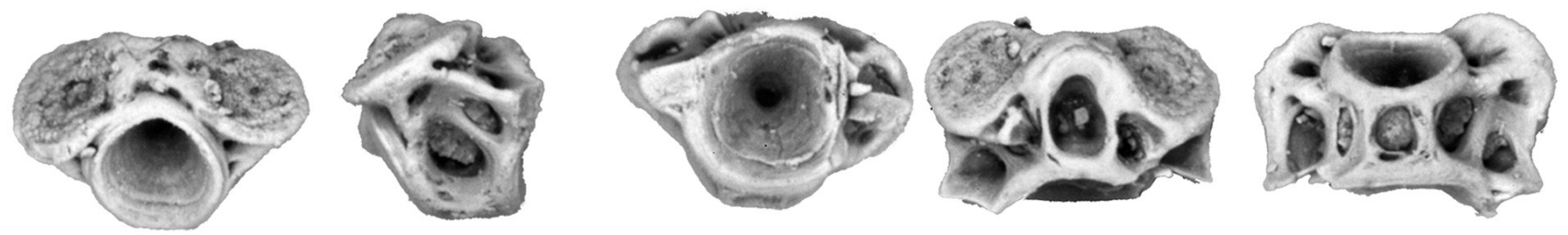

A
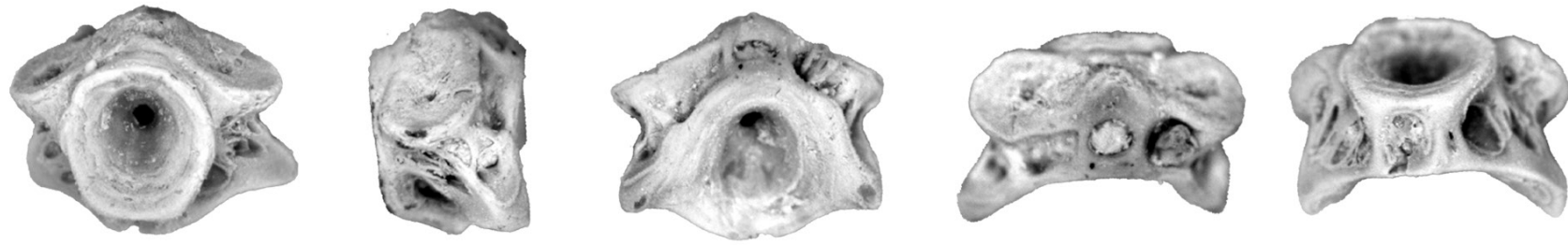

B
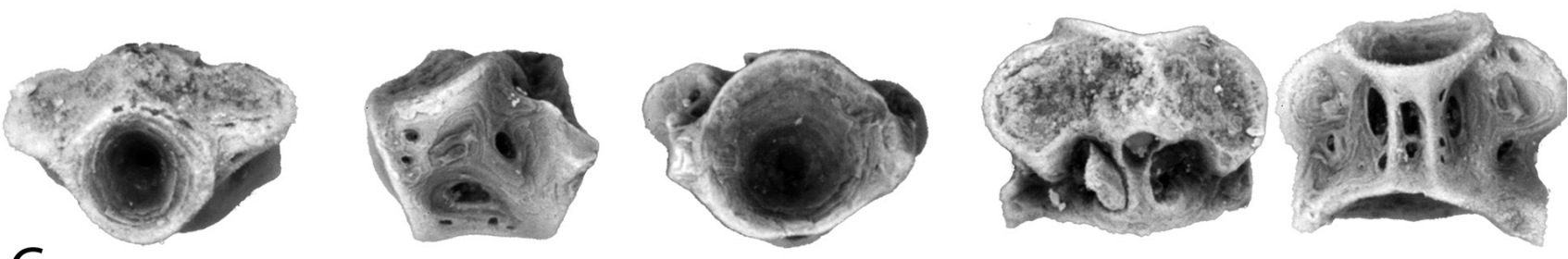

C
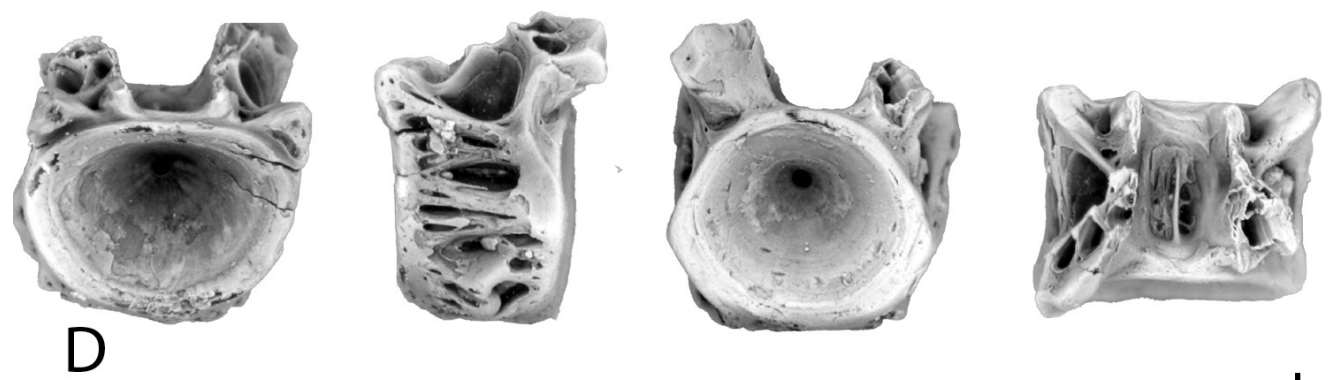

firises
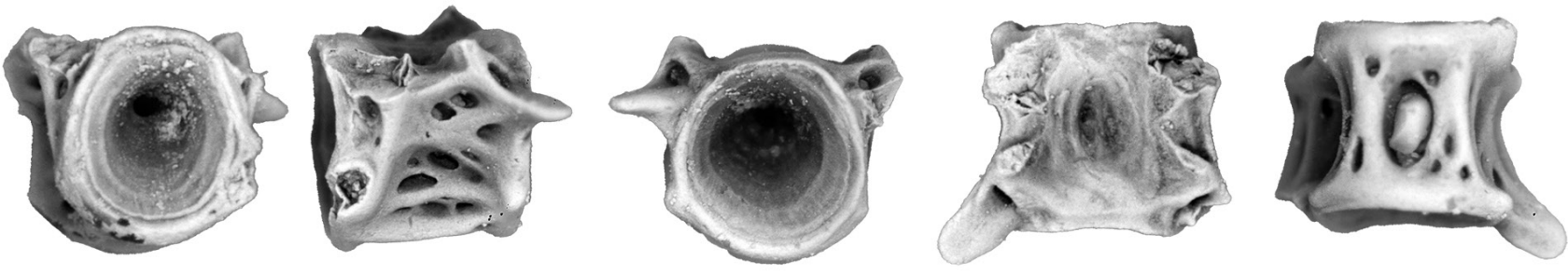

E
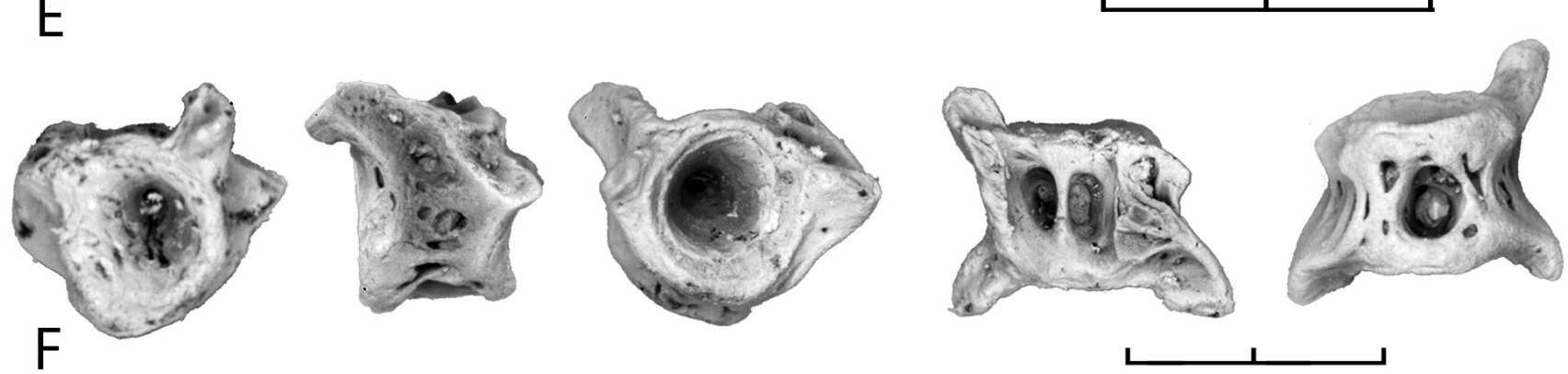